\title{
AGROMETEOROLOGIA
}

\section{PLASTICIDADE ANATÔMICA DA FOLHA DE TARO CULTIVADO SOB DIFERENTES CONDIÇÕES DE SOMBREAMENTO}

\author{
ANCÉLIO RICARDO DE OLIVEIRA GONDIM $\left({ }^{2}\right)$; MÁRIO PUIATTI $\left({ }^{3, *}\right)$; \\ MARÍLIA CONTIN VENTRELLA $\left({ }^{4}\right)$; PAULO ROBERTO CECON $\left({ }^{5}\right)$
}

\begin{abstract}
RESUMO
O cultivo consorciado pode levar ao sombreamento de uma das culturas acarretando alterações morfológicas externas e internas e na produtividade da cultura sombreada. O taro [Colocasia esculenta (L.) Schott], é uma Araceae de ciclo cultural longo, o que dificulta seu cultivo em propriedades com limitação de área. A associação do taro com outras culturas é uma opção para situações dessa natureza; todavia, definir o nível de tolerância das plantas de taro ao sombreamento é de fundamental importância para se planejar seu cultivo no sistema de consórcio. O trabalho teve como objetivo avaliar as alterações anatômicas quantitativas em folhas e rizomas de taro 'Japonês', cultivadas sob intensidades de sombreamento de $0 \%, 18 \%, 30 \%$ e $50 \%$, visando obter subsídios para entender a redução de produtividade quando consorciada com espécies de maior porte. $\mathrm{O}$ aumento do sombreamento promoveu mudanças na proporção de células e tecidos, como redução da espessura da folha, do parênquima paliçádico e do aerênquima e da densidade de estômatos. Pode-se concluir que o taro possui plasticidade anatômica da lâmina foliar quando submetido a diferentes intensidades de sombreamento, o que provavelmente interfere na sua capacidade fotossintética e na redistribuição de fotoassimilados nos órgãos vegetativos.
\end{abstract}

Palavras-chave: Colocasia esculenta, anatomia quantitativa, nível de luz, amido.

\section{ABSTRACT \\ LEAF PLASTICITY IN TARO PLANTS UNDER DIFFERENT SHADE CONDITIONS}

The intercropping system can cause shading of one associated crop, leading to morphological, anatomical and yield changes in the shaded crop. The taro [Colocasia esculenta (L.) Schott] crop, is a long cicle Araceae species, that is difficult for cultivated in small properties. The association of taro plants with other crops is an option in these situations. However defining the tolerance level of taro plants to shading is an important point to design the associated system. The aim of this work was to evaluate quantitative anatomical characteristics in taro 'Japonês' leaves and rhyzomes. In order to understand the yield decrease in intercropping with other taller species taro plants were grown under $0 \%, 18 \%, 30 \%$ and $50 \%$ of shading. The increase on shadding induced changes in cells and tissues proportion, such as a reduction on leaf thickness, palisade parenchyma and aerenchyma thickness and on stomata density. It is concluded that taro plants show leaf anatomical plasticity under different shade levels, what probabily changes the photosynthetic capacity and photosynthate distribution in vegetative organs.

Key words: Colocasia esculenta, quantitative anatomy, light level, starch.

( ${ }^{1}$ ) Parte da dissertação de mestrado do primeiro autor. Recebido para publicação em 2 de julho de 2007 e aceito em 28 de maio de 2008.

$\left({ }^{2}\right)$ Departamento de Produção Vegetal, Universidade Estadual Paulista, Faculdade de Ciências Agrárias e Veterinárias, 14884-900 Jaboticabal (SP). E-mail: anceliogondim@hotmail.com

( $\left.{ }^{3}\right)$ Departamento de Fitotecnia, Universidade Federal de Viçosa, 36570-000 Viçosa (MG). E-mail: mpuiatti@ufv.br ( ${ }^{*}$ ) Autor correspondente.

(4) Departamento de Biologia Vegetal, Universidade Federal de Viçosa. E-mail: ventrella@ufv.br

$\left({ }^{5}\right)$ Departamento de Informática Universidade Federal de Viçosa. E-mail: cecon@dpi.ufv.br 


\section{INTRODUÇÃO}

As plantas podem ser muito influenciadas pela intensidade de luz recebida durante o crescimento e desenvolvimento. Em folhas aclimatadas às condições de sol ou sombra, constatam-se mudanças anatômicas e fisiológicas; folhas a pleno sol são geralmente espessas e têm maior capacidade fotossintética por unidade de área, devido ao incremento da quantidade de enzimas e maior condutância estomática, que folhas sombreadas (LARCHER, 2000). Aumento na intensidade de luz proporciona aumentos na espessura da folha, na massa foliar específica, no desenvolvimento da epiderme e do parênquima, bem como no número total de células das folhas (DiCKISON, 2000), porém pode promover diminuição dos fotoassimilados dirigidos aos órgãos de reserva por aumentar seu direcionamento para as regiões meristemáticas (CRAKER et al., 1983). Em batata, a redução da luminosidade promove redução da taxa assimilatória líquida, acúmulo de biomassa e alteração da distribuição da biomassa em favor de outros órgãos que não os tubérculos (Nösberger e Humphriess,1965, apud Gawronska e Dwelle,1989). Em rabanete, o aumento do sombreamento de 0 para $50 \%$ prolonga o ciclo da cultura e a expansão da área foliar, afetando a produção de raízes tuberosas (SouzA et al., 1999).

A capacidade de alterar a estrutura das folhas em resposta a diferentes níveis de luz é um atributo comum das espécies com amplo potencial de aclimatação (LARCHER, 2000). A adaptação da planta ao ambiente de luz depende do ajuste de seu aparelho fotossintético, de modo que a luminosidade ambiental possa ser utilizada da maneira mais eficiente possível, e as respostas dessas adaptações serão refletidas no crescimento global da planta. Assim, a eficiência do crescimento pode ser relacionada à habilidade de adaptação das plantas às condições de intensidade luminosa do ambiente, estando os efeitos mais significativos da intensidade de luz relacionados aos aspectos qualitativos (Амо, 1985). O efeito do sombreamento sobre as plantas depende da intensidade e da duração do sombreamento somados ao estádio de desenvolvimento das plantas (Escalante-Estrada e Kohashi-Shibata, 1982).

O taro, Colocasia esculenta (L.) Schott, é a principal hortaliça da família Araceae, cultivado há mais de 2.000 anos, e seus rizomas, ricos em amido, são utilizados na alimentação humana. A planta se caracteriza pela capacidade de crescer em condições consideradas adversas a outras espécies, como excesso de água, elevada temperatura e habitat sombreado, como florestas tropicais (IMBERT et al., 2004). Embora seja uma espécie considerada adaptada à sombra, sendo cultivada em muitos países da América Central em consórcio com bananeira, no Brasil e Havaí, cultivos comerciais de taro são realizados a pleno sol; nessas condições, podem-se observar injúrias foliares em períodos de intensa irradiância (Puiatti, 2002; Oliveira, 2004). Trabalhos em que se relata o efeito da intensidade de radiação solar sobre aspectos anatômicos e fisiológicos da espécie são incipientes, apesar de fundamentais para explicar o comportamento produtivo sob condições de cultivo.

O trabalho teve como objetivo avaliar o efeito de diferentes intensidades de sombreamento sobre aspectos anatômicos quantitativos da lâmina foliar de taro 'Japonês', e verificar possíveis variações na área ocupada por amiloplastos do rizoma.

\section{MATERIAL E MÉTODOS}

O material vegetal utilizado foi C.esculenta (L.) Schott (Araceae), comercializado como taro 'Japonês' (BGH 5925). Foram utilizados, como muda, rizomasfilho com massa média de $100 \mathrm{~g}$, obtidos do banco de germoplasma de hortaliças da UFV (BGH-UFV).

O experimento foi constituído de quatro tratamentos, correspondentes a três intensidades de sombreamento artificial $(18 \%, 30 \%$ e $50 \%)$, além do controle a céu aberto (luz plena). Foi desenvolvido na área da horta de pesquisas do Departamento de Fitotecnia da Universidade Federal de Viçosa (UFV), no período de $8 / 10 / 2004$ a 8/04/2005, localizada a $20^{\circ} 45^{\prime} \mathrm{LS}, 42^{\circ} 51^{\prime} \mathrm{LW}$ e altitude de $652 \mathrm{~m}$. Os valores médios mensais de precipitação pluvial, insolação média diária e das temperaturas máxima, média e mínima do ar, registrados durante a realização do experimento, estão relacionados na tabela 1 .

A área experimental é de topografia suave e o solo, classificado como Argissolo Vermelho-Amarelo Câmbico com textura argilosa, nas análises químicas, revelou os seguintes valores: $\mathrm{pH}\left(\mathrm{H}_{2} \mathrm{O}\right)=5,7 ; \mathrm{H}+\mathrm{Al}$ $=2,97 ; \mathrm{P}=41,9$ e $\mathrm{K}=81 \mathrm{mg} \mathrm{dm}^{-3} ; \mathrm{Ca}=2,8$ e $\mathrm{Mg}=0,7$ $\mathrm{cmol}_{\mathrm{C}} \mathrm{dm}^{-3}$; matéria orgânica $=20,8 \mathrm{dag} \mathrm{kg}^{-1} ; \mathrm{Zn}=5,1$; $\mathrm{Fe}=38,5 ; \mathrm{Mn}=32,7 ; \mathrm{Cu}=2,9$ e B $=0,57 \mathrm{mg} \mathrm{dm}^{-3}$. No solo, após preparado com aração e gradagem, foram abertos sulcos com profundidade de aproximadamente $0,12 \mathrm{~m}$, espaçados de $1,0 \mathrm{~m}$, seguido da distribuição das mudas a cada $0,30 \mathrm{~m}$ e do fechamento dos sulcos.

Utilizou-se o delineamento experimental em blocos casualizados, com quatro repetições. A parcela experimental foi constituída de três linhas de 1,80 m, contendo seis plantas cada uma. Consideraram-se como úteis as duas plantas centrais da fileira central. 
Tabela 1. Precipitação pluvial acumulada no mês (PP) e insolação média diária no mês (Insol) incidentes na área toda e médias mensais das temperaturas $\left({ }^{\circ} \mathrm{C}\right)$ máxima (Tmáx.), média (Tméd.) e mínima (Tmín.) do ar registradas nos tratamentos-controle (cultivo a pleno sol $=$ SOL) e sob intensidades de sombreamento de $18 \%$, 30\% e $50 \%$ durante o período do experimento de campo

\begin{tabular}{|c|c|c|c|c|c|c|c|c|c|c|c|c|c|c|}
\hline \multirow{2}{*}{$\begin{array}{l}\text { Mês/ } \\
\text { Ano }\end{array}$} & \multicolumn{2}{|c|}{ Área Toda } & \multicolumn{3}{|c|}{ SOL } & \multicolumn{3}{|c|}{18} & \multicolumn{3}{|c|}{30} & \multicolumn{3}{|c|}{50} \\
\hline & $\mathrm{PP}$ & Insol & T máx & $\mathrm{T}$ méd & T mín & $\mathrm{T}$ máx & $\mathrm{T}$ méd & $\mathrm{T}$ mín & $\mathrm{T}$ máx & $\mathrm{T}$ méd & $\mathrm{T}$ mín & T máx & T méd & T mín \\
\hline & $\mathrm{mm}$ & $\mathrm{h}$ & & & & & & 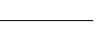 & & & & & & \\
\hline Out./04 & 66,2 & 4,64 & 40,9 & 28,8 & 16,7 & 40,1 & 27,8 & 15,5 & 39,1 & 26,9 & 14,7 & 37,6 & 25,8 & 14,0 \\
\hline Nov/ 04 & 195,9 & 4,79 & 43,3 & 30,9 & 18,5 & 41,0 & 29,5 & 18,0 & 39,4 & 28,5 & 17,5 & 37,9 & 27,5 & 17,0 \\
\hline Dez/04 & 276,0 & 4,20 & 44,0 & 31,8 & 19,5 & 41,5 & 30,3 & 19,0 & 39,7 & 29,1 & 18,5 & 38,2 & 28,0 & 17,7 \\
\hline Jan./ 05 & 203,1 & 4,33 & 44,7 & 32,0 & 19,2 & 42,0 & 30,5 & 18,9 & 40,4 & 29,4 & 18,3 & 38,7 & 28,1 & 17,5 \\
\hline Fev/ 05 & 200,2 & 6,33 & 44,5 & 31,6 & 18,7 & 41,9 & 30,2 & 18,4 & 40,0 & 29,0 & 18,0 & 38,5 & 27,9 & 17,2 \\
\hline Mar/05 & 267,5 & 5,21 & 42,8 & 30,3 & 17,7 & 40,8 & 28,9 & 17,0 & 39,5 & 27,9 & 16,3 & 38,3 & 27,0 & 15,6 \\
\hline $\mathrm{Abr} / 05$ & 57,6 & 6,00 & 35,0 & 26,0 & 16,9 & 34,0 & 25,0 & 16,0 & 32,6 & 24,1 & 15,5 & 31,7 & 23,3 & 15,0 \\
\hline
\end{tabular}

As intensidades de sombreamento foram obtidas pela colocação de malhas Sombrite ${ }^{\circledR}$ cerca de 0,50 m acima do dossel, cobrindo toda a parcela, sendo elevadas conforme ocorria o crescimento das plantas em altura. De acordo com as recomendações para a cultura (PuiAtтi, 2002), foram realizadas capinas manual (quatro) e irrigações por aspersão, conforme a necessidade. Não foram realizadas fertilizações químicas ou orgânicas, nem aplicação de defensivos de qualquer natureza.

Em 8/4/2005 (180 dias após o plantio), colheram-se duas plantas centrais de cada parcela, das quais foram retiradas amostras de folhas e de rizomas-filho. Foi selecionada a primeira folha completamente expandida a partir do centro da roseta, de onde se retiraram amostras da região intervenal do limbo e da nervura de 2 . $^{\text {a }}$ ordem. No rizoma, retiraram-se amostras da região periférica, contendo a periderme. As amostras foram imediatamente acondicionadas em recipientes

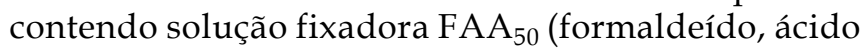
acético e álcool etílico 50\%, na proporção de 5:5:90, $\mathrm{v}: \mathrm{v}: \mathrm{v})$, por aproximadamente 48 horas e, em seguida, estocadas em álcool etílico 70\% (Johansen, 1940). Para as análises anatômicas, porções de $0,5 \times 0,5 \mathrm{~cm}$ de cada amostra foram desidratadas em série etílica e incluídas em metacrilato (Historesin-Leica), de acordo com as recomendações do fabricante, e seccionadas transversalmente em micrótomo rotativo com $6 \mu \mathrm{m}$ de espessura. As seções foram montadas sobre lâminas histológicas e coradas com azul de toluidina (O'BRIEN et al., 1964), por 10 minutos, para a coloração metacromática das estruturas celulares. As seções dos rizomas, após a coloração com azul de toluidina, foram tratadas com lugol (JOHANSEN, 1940), por um minuto, para a marcação de amido, que adquire a coloração negro-azulada com o reagente. As lâminas foram montadas com resina sintética (Permount). Para a análise de superfície e contagem dos estômatos, porções de aproximadamente $1 \mathrm{~cm}^{2}$ foram submetidas ao processo de diafanização, com hidróxido de sódio $10 \%$ por duas horas e hipoclorito de sódio $20 \%$ até o clareamento completo, intercalado por lavagens em água corrente, coradas com safrablau, desidratadas em série etílica/ xilólica e montadas com resina sintética (Permount).

Após a confecção e análise do laminário, imagens digitalizadas foram obtidas com fotomicroscópio (Olympus AX70) com sistema UPhoto acoplado a um microcomputador e analisadas com o software Image Pro-Plus 4.0. Na região intervenal do limbo, foram mensurados a área total da seção transversal, de parênquima paliçádico, de espaços intercelulares do parênquima lacunoso e de epiderme das faces abaxial e adaxial, espessura da folha, espessura do parênquima paliçádico e lacunoso e comprimento e largura das células do parênquima paliçádico. Na região das nervuras de segunda ordem foram mensuradas: área total da seção transversal, de parênquima paliçádico, de parênquima cortical, de feixe vascular e de colênquima. Nos rizomas-filho foram mensuradas a área total da seção transversal e a área ocupada por amiloplastos. As medidas de área foram transformadas em porcentagem em relação à área total avaliada. A contagem dos estômatos foi realizada em câmara clara acoplada a microscópio de luz, em 10 campos por repetição. A utilização de 10 campos por repetição (quatro) por tratamento foi estabelecida pela relativa homogeneidade de distribuição de estômatos na superfície foliar.

Os dados foram submetidos à análise de variância e as médias de cada tratamento (intensidade de sombreamento) comparadas com a da testemunha, adotando-se o teste de Dunnett a 5\% de probabilidade. 


\section{RESULTADOS E DISCUSSÃO}

Seções transversais de folhas e rizomas de taro desenvolvidos sob intensidades de sombreamento são apresentadas nas figuras 1 a 16, e respostas anatômicas quantitativas estão listadas na tabela 2 .

A folha de taro é dorsiventral e, na região intervenal, o mesofilo é formado por parênquima paliçádico voltado para a face adaxial e parênquima lacunoso voltado para a face abaxial (Figuras 1 e 2). Em taro, o parênquima lacunoso caracteriza-se pelos grandes espaços intercelulares e, nesse trabalho, o termo aerênquima é utilizado como referência a esse tecido. A área total da seção transversal do limbo na região intervenal diminuiu com o sombreamento, refletindo na diminuição da espessura da folha (Figuras 1, 3, 5 e 7). A espessura do limbo diminuiu com o sombreamento a partir de $30 \%$, chegando a $22 \%$ de redução com $50 \%$ de sombreamento durante o cultivo. Redução da espessura da folha é verificada em várias espécies cultivadas sob condições de sombreamento (Yun e TAYLOR, 1986; Sims e PearsY, 1992; Voltan et al., 1992; LeE et al., 2000; Feild et al., 2001; Piel et al., 2002; Morais et al., 2004). Folhas produzidas sob condições de alta luminosidade tendem a ser menores e mais espessas, com aumento de mesofilo por unidade de área, menor quantidade de espaços intercelulares no mesofilo, maior densidade de estômatos e de nervuras, quando comparadas a folhas expostas ao sombreamento. Essas variações estruturais são associadas com a regulação da difusão luminosa e gasosa dentro da folha, maximizando a eficiência fotossintética (EsAu, 1977; Dickison, 2000; TERASHIMA et al., 2006).

Essa variação na espessura do limbo foliar se deve tanto à diminuição da espessura do parênquima paliçádico como do aerênquima. Houve redução de $34,14 \%$ na espessura do parênquima paliçádico e de $29,3 \%$ na espessura do aerênquima em plantas de taro cultivadas sob $50 \%$ de sombreamento. Embora a porcentagem de espaços intercelulares do aerênquima na região intervenal não tenha se alterado significativamente com a variação na intensidade luminosa, em várias espécies é comum o aumento dos espaços intercelulares no mesofilo com o sombreamento (Voltan et al., 1992; Morais et al., 2004).

A diminuição da espessura do parênquima paliçádico em relação ao sombreamento pode ser explicada pela diminuição do comprimento e da largura das células que compõem esse tecido. A redução média foi de até $43 \%$ no comprimento e de $30,6 \%$ na largura das células do parênquima paliçádico com o maior nível de sombreamento imposto. O parênquima paliçádico tende a ser mais compacto e a ter maior número de camadas e/ou células mais alongadas em folhas desenvolvidas a pleno sol (Voltan et al., 1992; Vogelmann et al., 1996; Rôças et al., 1997; Morais et al., 2004; PANDEY e Kushwaha, 2005), o que é positivamente correlacionado com a capacidade fotossintética (Yun e Taylor, 1986; Sims e Pearsy, 1992; Dickison, 2000, Larcher, 2000; Piel et al., 2002; Morais et al., 2004; Pandey e Kushwaha, 2005).

A porcentagem de epiderme, em ambas as faces da folha, aumentou com o sombreamento, ao contrário dos outros tecidos analisados. O aumento foi de $6,5 \%$, $8,0 \%$ e $15,0 \%$ na face abaxial e $8,8 \%, 9,3 \%$ e $15,1 \%$ na face adaxial, respectivamente, em $18 \%, 30 \%$ e $50 \%$ de sombreamento em relação à testemunha. A plasticidade da epiderme é variável em relação a variações na intensidade luminosa, podendo diminuir (DICKISON, 2000; Pandey e Kushwaha, 2005; Gratani et al., 2006) ou aumentar (MorAis et al., 2004; VolTAN et al., 1992) sua proporção com o sombreamento. Considerando-se que as folhas de taro têm células epidérmicas em forma de papila, e que essa especialização das células epidérmicas funcionariam para concentrar a luz em plantas que se desenvolvem na sombra (FAHN, 1989; VogeLMANN et al., 1996), o aumento da área da epiderme sob sombreamento sugere uma tentativa de aclimatação da planta a essa condição.

O número de estômatos em ambas as faces da folha diminuiu a partir de $30 \%$ de sombreamento. O decréscimo no número de estômatos na face abaxial foi, respectivamente, de $16 \%$ e $23 \%$ nas folhas de plantas cultivadas a $30 \%$ e $50 \%$ de sombreamento, comparado ao controle. É comum a diminuição da densidade dos estômatos por unidade de área, que geralmente está relacionada ao aumento do tamanho das células epidérmicas em condições de maior sombreamento (VolTAN et al., 1992; RốçAs et al., 1997; Feild et al., 2001; Morais et al., 2004).

As nervuras de segunda ordem são bastante dilatadas, com grande proporção de tecidos fundamentais e numerosos feixes vasculares (Figuras 2, $4,6,8)$. A área total da seção transversal da nervura diminuiu com o sombreamento (Tabela 2). Nas nervuras de segunda ordem, o parênquima paliçádico é contínuo com a região intervenal e a porcentagem deste tecido não se alterou, significativamente, com o sombreamento. A área do parênquima cortical (parênquima de preenchimento + aerênquima) aumentou com o sombreamento, embora diferindo significativamente do controle somente no nível de $18 \%$ de sombreamento. O aerênquima é um tecido caracterizado pela presença de espaços intercelulares conspícuos, formando grandes lacunas (FAHN, 1989; EsAU, 1977); e a abundância de espaços intercelulares é característica comum em plantas desenvolvidas sob sombreamento (VoLTAN et al., 1992; RôÇAS et al., 1997; Morais et al., 2004). 

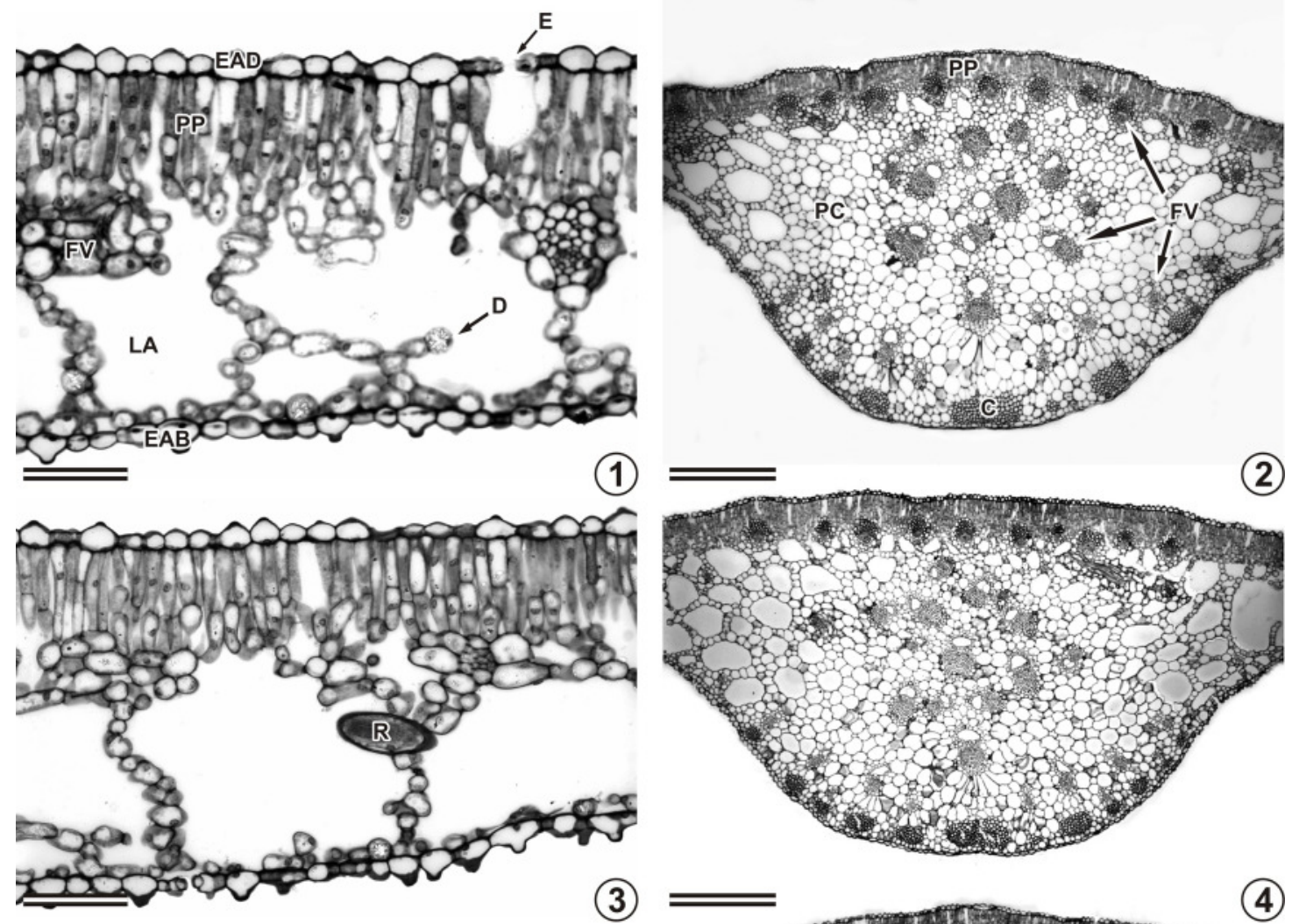

(2)

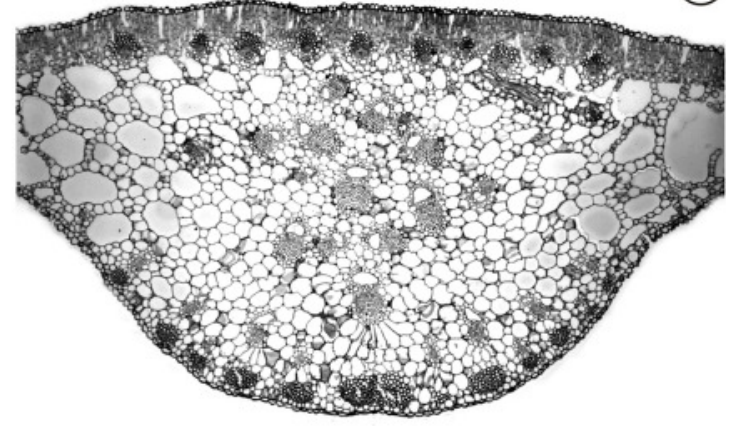

(3)
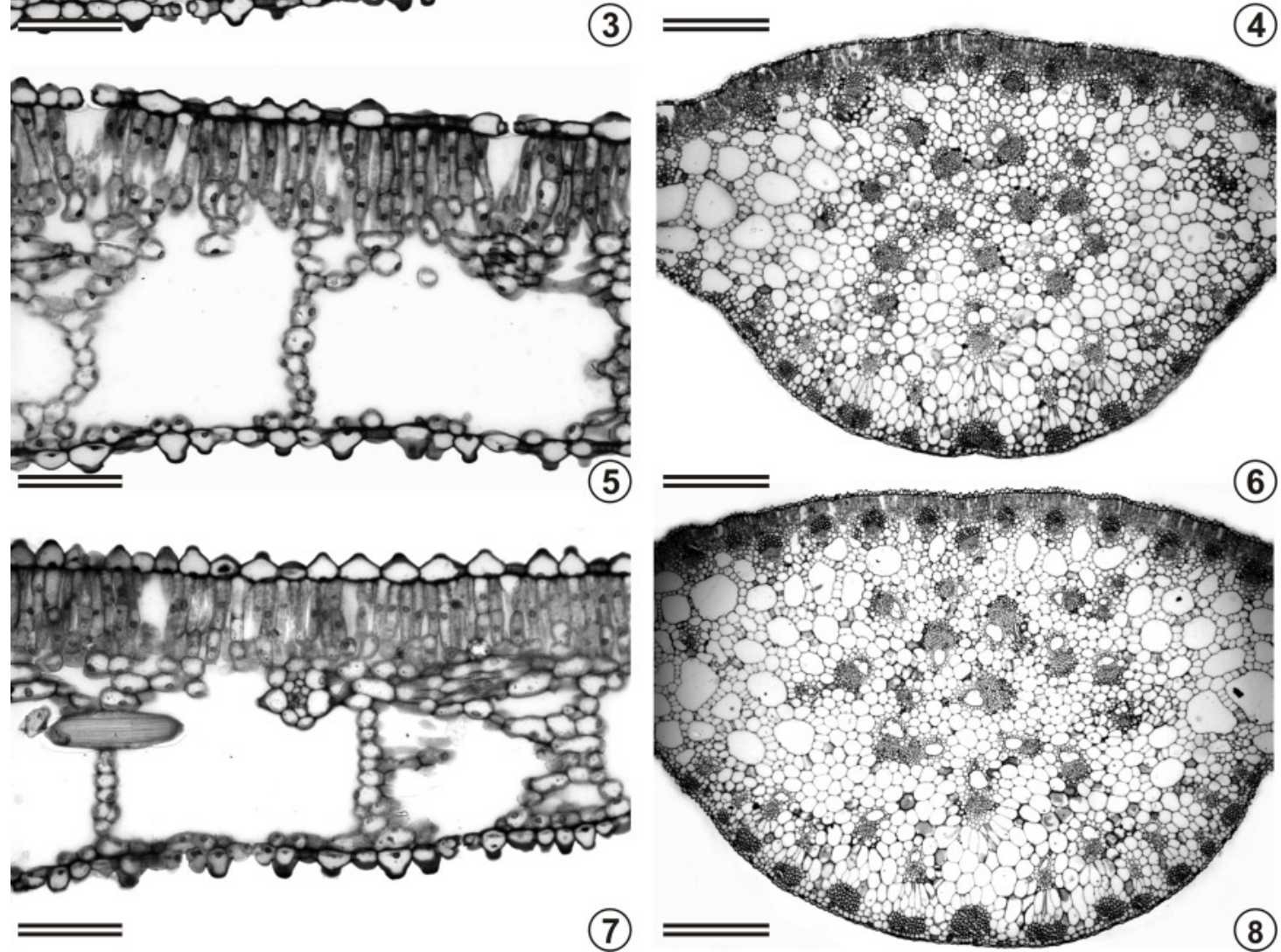

(6)

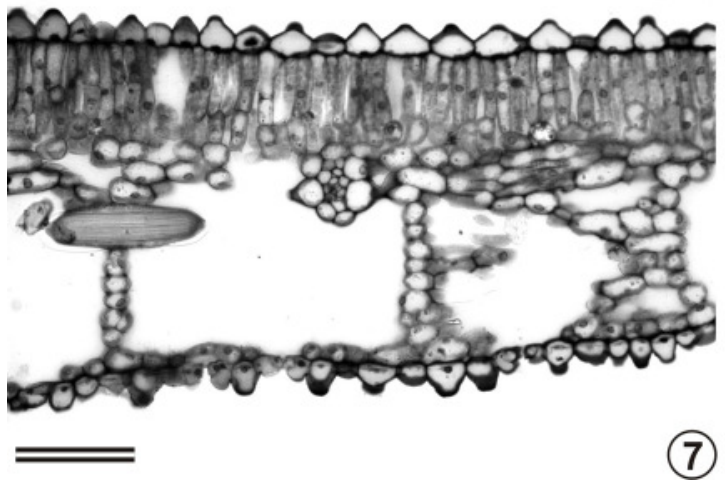

Figuras 1-8. Seções transversais de folhas de taro (Colocasia esculenta) 'Japonês' cultivado sob diferentes intensidades de sombreamento. 1 e 2: pleno sol (controle); 3 e 4: 18\% de sombreamento; 5 e 6: $30 \%$ de sombreamento; 7 e $8: 50 \%$ de sombreamento. 1, 3, 5 e 7 : região intervenal do limbo e barra $=100 \mu \mathrm{m} ; 2,4$, 6 e 8 : região da nervura e barra $=500 \mu \mathrm{m}$. C, colênquima; D, drusa; EAD, epiderme da face adaxial; EAB, epiderme da face abaxial; E, estômato; FV, feixe vascular; LA, lacuna do aerênquima; PC, parênquima cortical; PP, parênquima paliçádico; R, ráfide. 

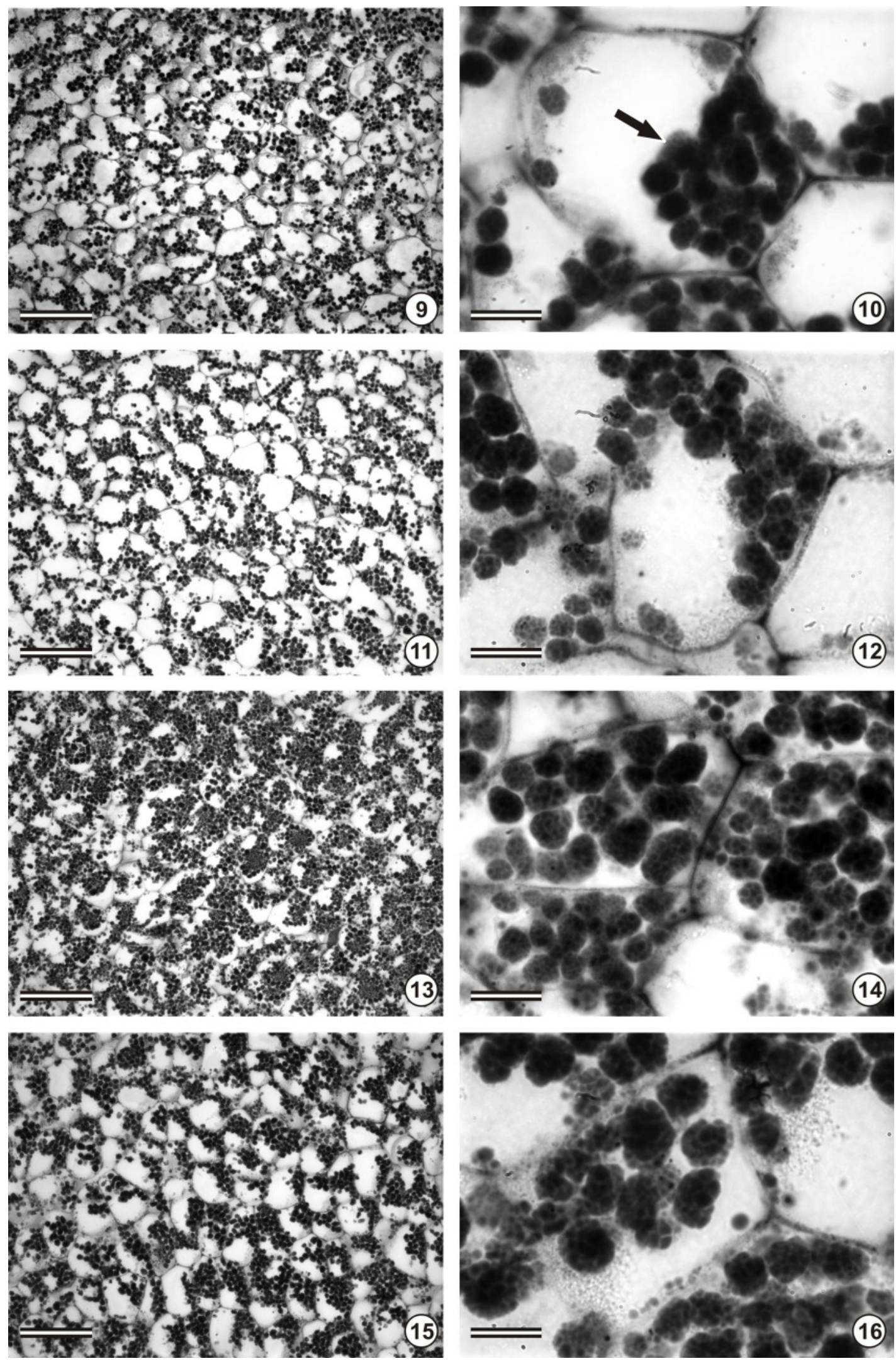

Figura 9-16. Seções transversais de rizomas-filho de taro (Colocasia esculenta) 'Japonês' cultivado sob diferentes intensidades de sombreamento. Observar reação positiva para amido com lugol (seta). 9-10: pleno sol (controle); 11-12: $18 \%$ de sombreamento; 13-14: 30\% de sombreamento; 15-16: 50\% de sombreamento. 9, 11, 13 e 15: barra = 200 $\mu \mathrm{m} ; 10,12,14$ e 16 : barra $=25 \mu \mathrm{m}$ 
Tabela 2. Características anatômicas avaliadas em folhas e rizomas-filho de taro (Colocasia esculenta) 'Japonês' cultivado sob diferentes intensidades de sombreamento

\begin{tabular}{llcrr}
\hline \multirow{2}{*}{ Característica } & \multicolumn{4}{c}{ Intensidade de sombreamento } \\
\cline { 2 - 3 } & 0 & 18 & 30 & 50 \\
\hline
\end{tabular}

Região intervenal do limbo

Área total da seção transversal do limbo $\left(\mu \mathrm{m}^{2}\right)$

$\%$ epiderme da face adaxial

\begin{tabular}{ccccc}
459309,9 & $398412,9^{*}$ & $378666,9^{*}$ & $339009,3^{*}$ & 6,45 \\
5,57 & $6,11^{*}$ & $6,14^{*}$ & $6,56^{*}$ & 2,90 \\
5,60 & $5,99^{*}$ & $6,09^{*}$ & $6,59^{*}$ & 3,91 \\
26,62 & $28,22^{*}$ & $27,64^{*}$ & $23,62^{*}$ & 6,61 \\
28,03 & $29,0^{\mathrm{ns}}$ & $28,67^{\mathrm{ns}}$ & $27,45^{\mathrm{ns}}$ & 5,40 \\
374,12 & $329,96^{\mathrm{ns}}$ & $318,32^{*}$ & $291,94^{*}$ & 7,02 \\
67,31 & $56,19^{*}$ & $42,61^{*}$ & $38,32^{*}$ & 2,68 \\
18,17 & $16,27^{*}$ & $14,77^{*}$ & $12,61^{*}$ & 3,31 \\
111,31 & $99,29^{\mathrm{ns}}$ & $85,34^{*}$ & $77,31^{*}$ & 9,05 \\
200,37 & $180,36^{*}$ & $173,01^{*}$ & $141,67^{*}$ & 7,71 \\
123,75 & $114,25^{\mathrm{ns}}$ & $103,75^{*}$ & $95,75^{*}$ & 5,89 \\
58,13 & $52,50^{\mathrm{ns}}$ & $30,00^{*}$ & $26,88^{*}$ & 9,65 \\
& & & & \\
4700206,8 & $4411819,0^{*}$ & $4047266,5^{*}$ & $3866492^{*}, 8^{*}$ & 6,19 \\
6,23 & $6,15^{\mathrm{ns}}$ & $5,96^{\mathrm{ns}}$ & $5,27^{\mathrm{ns}}$ & 4,60 \\
72,20 & $77,34^{*}$ & $76,71^{\mathrm{ns}}$ & $73,60^{\mathrm{ns}}$ & 1,42 \\
11,50 & $13,24^{*}$ & $14,72^{*}$ & $15,55^{*}$ & 5,87 \\
3,52 & $3,83^{\mathrm{ns}}$ & $4,39^{*}$ & $4,96^{*}$ & 4,47 \\
& & & & \\
49,67 & $44,07^{\mathrm{ns}}$ & $43,70^{\mathrm{ns}}$ & $41,69^{\mathrm{ns}}$ & 6,13 \\
\hline
\end{tabular}

$\%$ epiderme da face abaxial

\% parênquima paliçádico

\% espaços intercelulares do aerênquima

Espessura do limbo foliar $(\mu \mathrm{m})$

Comprimento de células do parênquima paliçádico $(\mu \mathrm{m})$

Largura de células do parênquima paliçádico $(\mu \mathrm{m})$

Espessura do parênquima paliçádico $(\mu \mathrm{m})$

Espessura do aerênquima $(\mu \mathrm{m})$

Número de estômatos na face abaxial $\left(\mathrm{mm}^{2}\right)$

Número de estômatos na face adaxial $\left(\mathrm{mm}^{2}\right)$

Região da nervura de $2^{\text {a }}$ ordem

Área total da seção transversal da nervura $\left(\mu \mathrm{m}^{2}\right)$

\% parênquima paliçádico

\% parênquima cortical (preenchimento + aerênquima)

$\%$ feixe vascular

$\%$ colênquima

Rizoma-filho

$\%$ amiloplasto

49,67

(*) Significativo e (ns) não significativo a 5\% de probabilidade, em relação ao controle, pelo teste de Dunnett.

Valores em \% são reais, todavia os dados originais foram transformados em vx+1 para realização da análise estatística.

O colênquima, tecido de sustentação localizado na região das nervuras de maior calibre, está distribuído em cordões, tanto na face adaxial, acompanhando os feixes vasculares, como na face abaxial, onde aparece como cordões isolados (Figura $2,4,6,8)$. A porcentagem de colênquima na seção transversal da folha aumentou significativamente a partir de $30 \%$ de sombreamento (Tabela 2). O aumento médio do colênquima chegou a $29 \%$ em plantas cultivadas a $50 \%$ de sombreamento, o que pode estar relacionado ao aumento da área foliar em condições de maior sombreamento e ao equilíbrio da arquitetura foliar com o incremento de tecido de sustentação. A porcentagem de área ocupada pelo feixe vascular na nervura de segunda ordem também aumentou com os níveis de sombreamento, chegando a $26 \%$ de aumento em plantas desenvolvidas a $50 \%$ de sombreamento. Ao contrário do observado em taro, geralmente ocorrem maiores proporções de tecidos vasculares e de sustentação em plantas que se desenvolvem sob maior intensidade luminosa (RôçAs et al., 1997; LEE et al., 2000; DiCKISON, 2000).

A porcentagem de área ocupada por amiloplastos na seção transversal de rizomas-filho (Figuras 9-16, Tabela 2) é uma medida indireta da presença de amido, e não houve diferenças significativas em relação ao controle. Enquanto rizomas de plantas cultivadas sob luz plena (Figuras 9 e 10), tiveram acúmulo médio de amiloplastos de $49,67 \%$ por seção transversal de rizoma, em rizomas de plantas cultivadas sob 50\% de sombreamento (Figura 15 e 16), o acúmulo médio foi de apenas 41,69\% (Tabela 2), o que corresponde a 16,07\% de diminuição. Embora essa diminuição represente apenas uma tendência, uma vez que a porcentagem de amiloplastos por área não foi estatisticamente significativa pelo teste de médias utilizado, pode ser relevante no rendimento de amido por rizoma, e por área, e pode refletir nas qualidades culinárias do produto. 
Portanto, maiores intensidades de sombra promoveram alterações anatômicas nos tecidos foliares, o que pode ter afetado as rotas metabólicas que determinam a quantidade de carbono fixado nos cloroplastos, reduzindo o transporte de açúcares alocados para os tecidos de reservas (rizomas). Além disso, restrição de luz pode promover alterações na anatomia e ultra-estrutura dos cloroplastos (CROOKSTON et al., 1975). Resultados semelhantes foram obtidos por HANG et al. (1984) os quais, estudando baixa intensidade de luz (75\%) na cultura do amendoim, verificaram redução na exportação total dos assimilados e na distribuição desses assimilados. NÖSBERger e Humphriess, em 1965 (apud GAWRONSKa e Dwelle, 1989), também verificaram em batata, que houve aumento no crescimento vegetativo em detrimento dos tubérculos, com o aumento do sombreamento.

\section{CONCLUSÕES}

1. Observa-se no taro plasticidade anatômica da lâmina foliar quando submetido a diferentes intensidades de sombreamento, o que provavelmente interfere em sua capacidade fotossintética e redistribuição de fotoassimilados nos órgãos vegetativos.

2. O aumento do sombreamento promoveu, principalmente, redução da espessura da folha e da densidade de estômatos, o que pode estar relacionado com a menor produtividade da cultura quando sombreada.

\section{AGRADECIMENTOS}

À CAPES pela bolsa de estudos disponibilizada ao primeiro autor do artigo.

\section{REFERÊNCIAS BIBLIOGRÁFICAS}

AMO, S.R. del. Algunos aspectos de la influencia de la luz sobre el crecimiento de estados juveniles de especies primarias. In: GOMES-POMPA, A.L. Regeneracion de selvas. México: Alhamba Mexicana, 1985. p.79-90.

CRAKER, L.E.; SEIBERT, M.; CLIFFORD, J.T. Growth and development of radish (Raphanus sativus L.) under selected light environments. Annals of Botany, London, v.51, n.1, p.5964, 1983.

CROOKSTON, R.K.; TREHARNE, K.J.; LUDFORD, P.; OZBUN, J.L. Response of beans to shading. Crop Science, Madison, v.15, n.6, p.412-416, 1975.

DICKISON, W.C. Integrative plant anatomy. San Diego: Academic Press. 2000. 533p.
ESAU, K. Plant Anatomy of seed plants. 2.ed. New York: John Wiley, 1977. 550p.

ESCALANTE-ESTRADA, J.A.S; KOHASHI-SHIBATA, J. Efecto del sombreamento artificial sobre algunos parametros del crescimento en frijól (Phaseolus vulgaris L.). Agrociencia, Chapingo, v.48, p.29-38, 1982.

FAHN A. Plant Anatomy. 3.ed. Oxford: Pergamon Press. $1989.544 p$

FEILD, T.S.; BRODRIBB, T.; JAFFRÉ, T.; HOLBROOK, N.M. Acclimation of leaf anatomy, photsynthetic light use, and xylem hydraulics to light in Amborella trichopoda (Amborellaceae). International Journal of Plant Science, v.162, n.5, p.999-1008, 2001

GAWRONSKA, H; DWELLE, R.B. Partitioning of photoassimilates by potato plants (Solanum tuberosum L.) as influence by irradiance: I. Partitioning patterns in cultivar Russet Burbank grown under high and low irradiance. American Potato Journal, Orono, v.66, n.4, p.201-213, 1989.

GRATANI, L.; COVONE, F.; LARCHER, W. Leaf plasticity in response to light of three evergreen species of the Mediterranean maquis. Trees, Berlin, v.20, p.549-558, 2006.

HANG, A.N.; McCLOUD, D.E.; BOOK, K.J.; DUCAN, W.G. Shade effects on growth, partitioning and yield components of peanuts. Crop Science, Madison, v.24, n.2, p.109-115, 1984.

IMBERT, D.; SAUR, E.; BONHEME, I.; ROSEAU, V. Traditional taro (Colocasia esculenta) cultivation in the swamp forest of Guadeloupe (F. W. I.): Impact on forest structure and plant biodiversity. Revista Écology, Terre Vie, v.59, n. 1-2, p.181189, 2004.

JOHANSEN, D.A. Plant microtechnique. New York: McGrawHill Book Co. Inc., 1940. 423p.

LARCHER, W. Ecofisiologia Vegetal. São Carlos: RiMa, 2000, 531p.

LEE, D.W.; OBERBAUER, S.F.; JOHNSON, P.; KRISHNAPILAY, B.; MANSOR, M.; MOHAMAD, H.; YAP, S.K. Effects of irradiance and spectral quality on leaf structure and function in seedlings of two Southeast Asian Hopea (Dipterocarpaceae) species. American Journal of Botany, Columbus, v.87, n.4, p.447-455, 2000.

MORAIS, H.; MEDRI, M.E.; MARUR, C.J.; CARAMORI, P.H.; RIBEIRO, A.M.A. GOMES, J.C. Modifications on Leaf Anatomy of Coffea arabica caused by Shade of Pigeonpea (Cajanus cajan). Brazilian Archives of Biology and Technology, v.47, n. 6, p. 863-871, 2004.

O'BRIEN, T.P., FEDER, N., McCULLY, M.E. Polychromatic staining of plant cell walls by toluidine blue. Protoplasm, v.59, n.2, p.368-373, 1964.

OLIVEIRA, F. L. Alternativas para o manejo orgânico do taro (Colocasia esculenta L. Schott) em condições edafoclimáticas no estado do Rio de Janeiro. Seropédica, RJ: UFRRJ, 2004. 96p. Dissertação (Doutorado em Fitotecnia). - Universidade Federal Rural do Rio de Janeiro, Seropédica. 
PANDEY, S.; KUSHWAHA, R. Leaf anatomy and photosynthetic acclimation in Valeriana jatamansi L. Grown under high and low irradiance. Photosynthetica, v. 43, n.1, p.85-90, 2005.

PIEL, C.; FRANK, E.; LE ROUX, X.; GENTY, B. Effect of local irradiance on $\mathrm{CO}_{2}$ conductance of mesophyll in walnut. Journal of Experimental Botany, Eynshan, v.53, n.379, p.2423-2430, 2002.

PUIATTI M. Manejo da cultura do taro. In: CARMO, C.A.S. (Ed.). Inhame e taro: sistema de produção familiar. Vitória, ES: Incaper. 2002. p. 203-252.

RÔÇAS, G.; BARROS, C.F.; SCARANO, F.R. Leaf anatomy plasticity of Alchornea triplinervia (Euphorbiaceae) under distinct light regimes in a Brazilian montane Atlantic rain forest. Trees, Berlin, v.11, n.8, p.469-473, 1997.

SIMS, D.A.; PEARCY, R.W. Response of leaf anatomy and photosynthetic capacity in Alocasia macrorrhiza (Araceae) to a transfer from low to high light. American Journal of Botany, Columbus, v.79, n.4, p.449-455, 1992.

SOUZA, J.R.P.; MEHL, H.Ó.; RODRIGUES, J.D.; PEDRAS, J.F. Sombreamento e o desenvolvimento e produção de rabanete. Scientia Agrícola, Piracicaba, v.56, n.4, Piracicaba, 1999.

TERASHIMA, I.; HANBA, Y. T.; TAZOE, Y.; VYAS, P.; YANO, $\mathrm{S}$. Irradiance and phenotype: comparative eco-development of sun and shade leaves in relation to photosynthetic $\mathrm{CO}_{2}$ diffusion. Journal of Experimental Botany, Eynshan, v. 57, n. 2, p. 343-354, 2006.

VOGELMANN, T.C.; NISHIO, J.N.; SMITH, W.K. Leaves and light capture: light propagation and gradients of carbon fixation within leaves. Trends in Plant Science, v.1, n.2, p.6570, 1996.

VOLTAN, R.B.Q.; FAHL, J.I.; CARELLI, M.L.C. Variação na anatomia foliar de cafeeiros submetidos a diferentes intensidades luminosas. Revista Brasileira de Fisiologia Vegetal, v.4, n.2, p.99-105, 1992.

YUN, J.I.; TAYLOR, S.E. Adaptative implications of leaf thickness for sun- and shade-grown Abutilon theophrasti. Ecology, Tempe, v.67, n.5, p.1314-1318, 1986. 